\title{
Clinical Profile and Outcome of Children of Aged 6 -59 Months Admitted with Severe Acute Malnutrition at Medical College, Silchar, Assam
}

\author{
Pathak Nripendra Nath ${ }^{1}$, Debnath Sanjib Kumar², Ray Prajnan Sankar ${ }^{3}$ \\ ${ }^{1}$ Associate Professor, ${ }^{2}$ Assistant Professor, ${ }^{3}$ Junior Resident, Department of Pediatrics, \\ Silchar Medical College, Assam, India
}

\begin{abstract}
Background: Inspite of significant economic improvement of India,prevalence of malnutrition specifically severe acute malnutrition is significantly high. According to NFHS-4(2015 -2016) report, 7.4\% of malnourished children are severely wasted in India and in Assam it is 6.2\%.Clinical profile of acute severe malnutrition (SAM) is different from place to place. Understanding of child health profile in different geographical area will help to prioritize intervention and resource allocation.

Material and Method: Hospital based prospective observational study carried out in the department of Pediatrics, Silchar Medical College, Assam, India from July 2018 to June 2019. 50 SAM children of aged 6 months to 59 months were included into the study after meeting the inclusion criteria. Historical,clinical and laboratory data were recorded in a predesigned proforma. Data were analysed using appropriate statistical method.
\end{abstract}

Results: The prevalence of severe acute malnutrition is $2.7 \%$. The mean age of study population is 21.86 \pm 14.85 months. $68 \%$ were male and $32 \%$ were female out of the 50 SAM children. Nonedematous SAM were more $(56 \%)$ than the edematous SAM (44\%).Highest incidence of SAM were in the age group of 6 -24 months (68\%).Almost all the cases (96\%) belonged to low SES.78\% mothers were either illiterate or primary school educated. EBF up to 6 months of age were only in $16 \%$ of cases. Major clinical presentation were diarrhea (70\%), fever (68\%), anorexia (66\%), ARI (56\%), vomiting (38\%), eye problems (38\%).Comorbid conditions associated with SAM were anemia (86\%), pneumonia (42\%), worm infestation (40\%) followed by UTI (38\%) \& tuberculosis (16\%). Recovery rate is $54 \%$. Mean hospital stay is $10.28 \pm 5.84$ days. 2 children (4\%) died during hospital stay.

Conclusion: Severe acute malnutrition is the most severe life threatening form of malnutrition which requires urgent attention. Timely identification and intervention of various risk factors,clinical and comorbid condition is likely to break the viscious cycle of undernutrition, infection and SAM and thereby improve outcome.

Keywords: Severe acute malnutrition,female literacy, socio-economic status,wasting.

\section{Introduction}

\section{Corresponding Author:}

\section{Debnath Sanjib Kumar}

Assistant Professor, Department of Pediatrics, Silchar

Medical College, Assam, India

e-mail:sanjibdn@gmail.com

Mobile No.: +917399215449
Malnutrition in children is the most serious health problem affecting globally till twenty first century with muchmore prevalentin the developing countriesincluding India. Many children die everyday directly or indirectly from malnutrition. With proper attention and nutritional therapy most of these deaths can be prevented. ${ }^{1}$ Severe acute malnutrition (SAM) is an unique type of severe 
malnutrition. It is the most severe and life threatening form of malnutrition in children and is responsible for high morbidity and mortality among malnourished children. ${ }^{2}$ Globally approximately 19 million children under five years of age suffered from SAM in 2015. ${ }^{3}$ The World Health Organization (WHO) has recommended this special classification for identifying and managing children with life threatening malnutrition. Severe acute malnutrition is defined as presence of any of the following I ) weight for height/length below -3 standard deviation (SD or Z score) of the median WHO growth reference ii) presence of bipedal nutritional edema or iii) mid upper arm circumference below $115 \mathrm{~mm}$ in the age group of 6 months to 59 months. ${ }^{4}$ A vast majority (over $90 \%$ ) of children with SAM is located in south and south east Asia and Sub Saharan Africa. India has the greatest population of severely malnourished children in the world and accounts for over $20 \%$ of under five childhood death every year and around 2.1 million children in this country do not survive to celebrate their first birthday. ${ }^{5}$ According to National Family Health Survey 4 (NFHS4, 2015 -2016) report, in India, 7.4\% of malnourished children are severely wasted (weight for height $<-3 \mathrm{SD}$ ) and in Assam, 6.2\% of under five children are severely wasted. ${ }^{6}$ Since wasting denotes acute malnutrition, these children are said to have severe acute malnutrition.

Better clinical characterization,triage and appropriate treatment of complications on admission along with nutritional therapy and targeted supportive treatment as outlined in the WHO protocol is associated with improved outcome. ${ }^{7}$

Clinical profile of severe acute malnutrition is different from place to place or region to region. As the underlying clinical factors, co morbidities and health system infrastructure differ in places and countries, understanding of the childhealth profile in different places will help to enable proper targeting and prioritizing of intervention and resource allocation. ${ }^{8}$

There is wide a variation of spectrum of nutritional disorders in this southern Assam, India, a geographically landlocked region with population of diverse ethnicity, multilinguality, religion and cultural practices with the rest of the country.

Objective: on the background of the above introduction, the present study was conducted with the objective of determining 1 . The prevalence of SAM in this region 2. The clinical profile associated with SAM like risk factors,co-morbid conditions and type of SAM 3. Outcome of SAM after hospitalization and treatment.

\section{Material and Method}

This hospital based prospective study was done in the department of Pediatrics, Silchar Medical College, Assam, India for a period of one year (July 2018 to June 2019). A total of 50 children of age 6 months to 59 months admitted in the department for severe acute malnutrition related complaints were included for study. The geographical locations of the study population were Barak Valley, Assam and neighbouring states. The children were enrolled for the study after satisfying the following inclusion and exclusion criteria.

\section{Inclusion Criteria:}

(i) $\mathrm{Wt}$ for $\mathrm{ht} /$ length $<-3 \mathrm{SD}$ or $\mathrm{Z}$ score of median $\mathrm{WHO}$ growth reference.

(ii) $\mathrm{MUAC}<11.5 \mathrm{~cm}$

(iii) Nutritional edema of feet.

\section{Exclusion Criteria:}

(i) Children with non nutritional causes of SAM.

(ii) Children with congenital anomalies,mental retardation,cerebral palsy, chronic renal diseases, congenital chronic hemolytic anemia.

Informed consent of parents was taken before inclusion to the study. Details clinical and laboratory parameters were recorded in a pre designed proforma. Anthropometry was done with electronic weighing machine with sensitivity of $\pm 10 \mathrm{gm}$, infantometer and stadiometer,narrow flexible nonstretchable measuring tape. Z score was calculated using WHO MGRS standard deviation chart. ${ }^{9}$ Laboratory tests like blood sugar(R),hemoglobin level, serum electrolytes, TC, DLC, $\mathrm{X}$-Ray chest, mantoux test, stool and urine forroutine and culture were routinely done. Other specific tests were done whenever necessary. Therapeutic management of all the cases was done according to the protocol of WHO and Indian Academy of Pediatrics(IAP). ${ }^{1,10}$

Discharge criteria. SAM cases were discharged when they met the following criteria.

1. Satisfactory weight gain i.e $>15 \%$ of admission weight.

2. Edema resolved. 
3. Return of good appetite.

4. Medical complications treated.

Statistical analysis of data was done using Statistical Package for Social Sciences (SPSS 16.0 version).

\section{Results}

1. Prevalence of SAM. The overall prevalence of severe acute malnutrition in our study population is $2.7 \%$.

2. Socio demographic profile (Table 1).

Table 1: Socio demographic profile

\begin{tabular}{|l|c|}
\hline 1. Gender & $n(\%)$ \\
Male & $34(68)$ \\
Female & $16(32)$ \\
\hline 2. Age in months (mean) & \\
$6-12(9.2)$ & $18(36)$ \\
$13-24(16.3)$ & $16(32)$ \\
$25-36(33.8)$ & $7(14)$ \\
$37-48(45.7)$ & $8(16)$ \\
$49-59$ & \\
\hline
\end{tabular}

\begin{tabular}{|l|c|}
\hline 3. Religion & $21(42)$ \\
Hindu & $28(56)$ \\
Islam & $1(2)$ \\
Christian & $n(\%)$ \\
\hline 4.Socio economic & \\
Status & $10(20)$ \\
Lower & $38(76)$ \\
Upper lower & $2(4)$ \\
Middle & $0(0)$ \\
Upper & \\
\hline 5.Parental & \\
literacy & \\
Illiterate/upto & \\
Primary. & $39(78)$ \\
Mother & $20(40)$ \\
Father & \\
Upto high school & $11(22)$ \\
Mother & $30(60)$ \\
Father & \\
\hline
\end{tabular}

Table 2: Clinical profile

\begin{tabular}{|l|l|l|l|}
\hline 1.Risk factors $n(\%)$ & 2.Type $n(\%)$ & 3.Clinical Presentation $n(\%)$ & 4.Co-morbity $n(\%)$ \\
\hline Low SES 48(96) & & & \\
No EBF 42(84) & & Diarrhoea 35(70) & Anemia 43(86) \\
Low maternal education & Fever 34(68) & Pneumonia 21(42) \\
$39(78)$ & Anorexia 33(66) & Worm \\
Delayed \& & 31(62) Edematous & ARI 28(56) & infestation 20(40) \\
thin complementary & $19(38)$ & Vomiting 19(38) & UTI 19(38) \\
feed 35(70) & & Eye problem 19(38) & TB 8(16) \\
Incomplete immunization & & Hypoglycemia 7(14) & \\
$35(70)$ & & & \\
\hline
\end{tabular}

Table 3: Outcome

\begin{tabular}{|c|c|c|c|c|c|}
\hline $\begin{array}{c}\text { Recovery (Wt gain }>15 \% \\
\text { of admission wt) } n(\%)\end{array}$ & $\begin{array}{l}\text { Non respondent (Wt gain } \\
\quad<10 \mathrm{gm} / \mathrm{kg} / \mathrm{day} n(\%)\end{array}$ & $\begin{array}{c}\text { Average Wt } \\
\text { gain gm/kg/day }\end{array}$ & $\begin{array}{c}\text { Defaulters } \\
n(\%)\end{array}$ & $\begin{array}{c}\text { Duration of hospital } \\
\text { stay. days (mean) }\end{array}$ & Death $n(\%)$ \\
\hline $27(54)$ & $15(30)$ & 7.5 & $6(12)$ & $10.28 \pm 5.84$ & $2(4)$ \\
\hline
\end{tabular}

\section{Discussion}

The prevalence of SAM in our study is $2.7 \%$ which is lower than the national prevalence (7.9\%, NFHS-3). Similar prevalence were reported by A S Bhadoria ${ }^{11}$ from northern India and H D Shewade ${ }^{12}$ from Puducherry as $2.2 \%$ and $3.6 \%$ respectively. Prevalence of SAM varies widely across the Indian states.
We observed that male children with SAM were almost twice as that of female (68\% vs 32\%).Similar findings were observed by few workers. ${ }^{13,14}$ However, studies by $\mathrm{M} \mathrm{B} \mathrm{Sing}^{15}$ and $\mathrm{S} \mathrm{Rao}^{16}$ found higher prevalence of SAM among girls. Higher prevalence in males in our study may be due to more importance given to male child for medical care because of societal attitude. 
Though our study population is from the Hindu majority area,more number of SAM (56\%) is seen amongst Muslim children. We could not correlate any association of prevalence of SAM with religion. This may because of small sample size and needs further socio- demographic studies.

The mean age of the study population is $21.86 \pm$ 14.85 months. Two third (68\%) of the total cases belong to the age group of $6-24$ months. Similar results also reported by Aguaya et al in studies in Jharkhand where $77.7 \%$ of SAM patients were below 2 years of age. ${ }^{17}$ More number of cases in our study is seen between 6-12 months. This may be due to late introduction of complementary feeds, inadequate (thin) food,less birth spacing.

Almost all the SAM cases in our study (96\%) belong to lower socio-economic class (Kuppuswamy scale IV and $\mathrm{V}$ ).No cases belong to upper $\mathrm{S} \mathrm{E}$ class. This indicates the unavailability of food,poor purchasing power,lack of nutrition knowledge in a deprived community. Similar observation was made in other study also. ${ }^{18}$

$78 \%$ of mothers and $40 \%$ fathers of SAM children were either illiterate or had only primary school education. Only 28\% mothers were high school educated. Parental education specially women literacy is the most important determinants of malnutrition. Educated mother will have a greater awareness of nutrition, balanced diet and health of their children. Several studies from Bangladesh and India ${ }^{19,20}$ observed such correlation between low parental education and malnutrition in children.

$84 \%$ of the SAM children did not receive exclusive breast feeding up to 6 months of age. Similarly 35(70\%) children had delayed start of complementary feeding with thin or watery food. These two-non EBF and improper complementary feeding caused SAM in majority of cases below 2 years of age. Similar observations were made by $\mathrm{K}$ Mishra et al in their study. ${ }^{21}$ Other risk factors observed likelow maternal education, incomplete immunization were 78 and $70 \%$ respectively. Out of 50 SAM cases, non edematous SAM was more $(62 \%)$ than edematous SAM in our study.

Diarrhoea (70\%) and fever $(68 \%)$ were the most common clinical presentation followed by anorexia (66\%), ARI (56\%), vomiting (38\%), eye problems (38\%) and hypoglycemia $14 \%$ of SAM cases. Similar findings were reported by R Kumar et $\mathrm{al}^{22}$ in their study.
Among the co-morbid conditions, 43 children $(86 \%)$ had anemia of varying grades. Prevalence of other co-morbid conditions were pneumonia $(42 \%)$, worm infestations (40\%), UTI (38\%) \& tuberculosis (16\%). These findings are consistent with previous reports. ${ }^{23}$

On analysis of outcome of SAM cases in this study, it is found that $54 \%$ recovered (wt gain $>15 \%$ of admission wt) and $30 \%$ did not respond (wt gain $<10$ $\mathrm{gm} / \mathrm{kg} /$ day) to treatment. Average weight gain and mean duration of hospital stay were $7.5 \mathrm{gm} / \mathrm{kg} /$ day and 10.28 \pm 5.84 days. Six children (12\%) defaulted \& 2(4\%) died during hospital stay. In a similar study by K Sing, N Badgaiyan and K P Kushwaha in Uttar Pradesh in 2010 ,they reported average weight gain as $7.3 \mathrm{gm} / \mathrm{kg} /$ day, average hospital stay of 13.2 days, recovery rate of $46.8 \%$ and discharge without recovery as $53.2 \%$ in their study. ${ }^{24}$

\section{Conclusion}

Severe acute malnutrition is the most severe and life threatening form of malnutrition which requires urgent attention. Timely identification and intervention of various risk factors, clinical and co-morbid conditions is likely to break the viscious cycle of undernutrition, infection and SAM and thereby improve outcome.

Abbreviation: SES-socio-economic status, Wtweight, SD-standard deviation, MUAC-mid upper arm circumference, ARI-acute respiratory infection.

Funding: None.

\section{Conflict of Interest: None.}

Ethical Approval: The study was approved by the Institutional Ethics committee, Silchar Medical College on 16.3.2018.

\section{References}

1. Ashworth A, Khanum S, Jackson A, Schofield C. Guidelines for the inpatient treatment of severely malnourished children. 2003, Geneva: World Health Organization.

2. Caulfield LE, de Onis M, Blossner M, Black RE. Undernutrition as underlying cause of child health associated with diarrhoea, pneumonia and measles. Am J Clin Nutr. 2004; 80(1): 193-198.

3. UNICEF. Management of severe acute malnutrition in children: working towards result at scale.New York;2015. 
4. World Health Organization. Guideline: Updates on the management of severe acute malnutrition in infants and children. World Health Organization. 2013.

5. UNICEF Geneva, Switzerland. The state of the world's children 2008. Child survival in Geneva UNICEF flagship report.

6. International Institute for Population Sciences (IIPS) and ICF 2017. National Family Health Survey (NFHS-4), 2015-16: India, Mumbai. IIPS.

7. Maitland K, Berkley JA, Shebbe M, Peshu N, English M, Newton CR. Children with severe malnutrition, can those at highest risk of death be identified with the WHO protocol? PLoS Med. 2006; 3(12): e 500-10.

8. Black RE, Morris SS, Bryce J. Where and why are 10 million children dying every year? Lancet. 2003 June 28; 361(9376): 2226-34.

9. Onis Mde. WHO child growth standards: length/ height for age, weight for age, weight for length, weight for height and body mass index for age: method and development.Geneva: World Health Organization, Department of Nutrition for Health and Development.2006.

10. Indian Academy of Pediatrics (IAP). IAP guidelines 2006 for hospital based management of severely malnourished children (adapted from WHO guidelines). Indian Pediatrics.2007; 44: 443-61.

11. Bhadoria AS, KapilU, [...] and Mohan A. Prevalence of severe acute malnutrition and associated sociodemographic factors among children aged 6 months to 5 years in rural population of Northern India: A population based survey. J Family Med Prim Care. 2017Apr-June; 6(2): 380-385.

12. Shewade HD, Sunderamurthy B, Jayakumar N, Ramadoss P. Prevalence of acute severe malnutrition (SAM) among under five children: A community based cross sectional study from Puducherry, India. Indian J Matern Child Health.2013;15:1-5.

13. Aneja B, Sing P, Tandon M, Pathak P, Sing C. Etiological factors of malnutrition among infants in two urban slums of Delhi. Indian Pediatrics.2001;38(2) 160-165.

14. Asraf S, Javed MT, Abbas N, Aysha H, Hameed S. Malnutrition in diseased children with reference to age, sex, socio-economic status and area of living. Int J Agri Biol. 2001;3(4): 419-422.
15. Sing MB, Fotedar R, Laxminarayan J, Anand PK. Studies on nutritional status of children aged 0-5 years in a drought affected desert area of western Rajasthan, India. Public Health Nutr.2006;9(8): 961-967.

16. Rao S, Joshi SB, Kelkar RS. Change in nutritional status and morbidity over time among preschool children from slums in Pune, India. Indian Pediatrics.200; 37(10): 1060-1671.

17. Aguayo VM, Jacob S, Badgaiyan N, Chandra P, Kumar A, Sing K. Providing care for children with severe acute malnutrition in India: new evidence from Jharkhand. Public Health Nutr.2014; 17(1):206-11.

18. Khanna Poonam, Kaur R, Sing T, Miller J, Sandhu AK, Jyoti. Prevalence and socio-demographic determinants of malnutrition in rural communities of district Fatehgarh Sahib, Punjab. Curr Res Nutr Food Sci Jour. 2017;5(3): 374-382.

19. Hasan MT, Soares Magalhaes RJ, Williams GM, Mamun AA. The role of maternal education in the 15 years trajectory of malnutrition in children under 5 years of age in Bangladesh. Matern Child Nutr. 2016; 12: 929-939.

20. Meshram II, Arlappa N, Balakrishna N, Rao KM, Laxmaiah A, Brahmam GN. Trends in the prevalence of undernutrition, nutrient $\&$ food intake and predictors of undernutrition among under five year tribal children in India. Asia Pacific J Clin Nutr.2012

21. Mishra K, Kumar P, Basu S, Rai K, Aneja S. Risk factors for severe acute malnutrition in children below 5 years of age in India: A case control study. The Indian Journal of Pediatrics. 2014 Aug 1; 81(8): 762-5.

22. Kumar R, Sing J, Joshi K, Sing HP, Bijesh S. Comorbidities in hospitalized children with severe acute malnutrition.Indian Pediatrics. 2014 Feb 1; 51(2):125-127.

23. Garg M, Devpura K, Saini SK, Kumara S. A hospital based study on co-morbidities in children with severe acute malnutrition. J Pediatr Res. 2017; 4(1): 82-88.

24. Sing K, Badgaiyan N, Kushwaha KP. Management of children with severe acute malnutrition in India: Experience of Nutrition Rehabilitation Centre in Uttar Pradesh, India. Indian Pediatrics.2012; 49: 181-185. 